\title{
Global Variations of Ionospheric Total Electron Content (TEC) Derived from GPS Global Ionospheric Maps
}

\author{
Hintsa Gebreselasse and Gebregiorgis Abraha* \\ Department of Physics, College of Natural and Computational Sciences, P.O.Box 231, Mekelle \\ University, Mekelle, Ethiopia (*ggabraha@yahoo.com.hk).
}

\begin{abstract}
This paper is aimed to investigate diurnal, monthly and seasonal variation of ionospheric total electronic content (TEC) obtained from two GPS satellites IGS and COD and to inspect mean VTEC Correlation between the two satellites by the year of 2008. TEC is defined by the integral of electron density in a $1 \mathrm{~m}^{2}$ column along the signal transmission path. It is an important parameter to monitor possible space weather impacts. The processed and archived data taken from IGS and COD satellites has been imported in to a MATLAB code which gave us the results of the value of VTEC. Results of the two satellites revealed that, Out of the selected equinox and solstice day's maximum value of TEC is recorded on March 20/2008 over North and South west equator due to the maximum solar radiation reaching to the ionosphere of the Earth. On the contrary, the Minimum peak ionospheric TEC value is recorded on June 21/2008 over south Asia particularly Srilanka and Bangladesh due to emission of low solar radiation. As regards to monthly variations of ionospheric TEC, results of IGS and COD satellites show that highest mean TEC value is recorded on March and July recorded the least peak TEC value. Results regarding to seasonal variation also revealed that E-Season recorded maximum TEC value and least TEC value is recorded on J-Season. The observations of the two satellites also show that the mean TEC value presents stronger solar activity sensitivity at lower-latitude bands than the middle and high latitudes. In general, there was a very high correlation between Mean TEC value recorded by IGS and COD satellites by the year of 2008 in all low, middle and high latitudes.
\end{abstract}

Keywords: IGS and COD satellites, GPS, Ionosphere, Low, middle and high-latitudes, TEC.

\section{INTRODUCTION}

It is well known that the variations of the Earth's ionosphere are complicated and may behave quite differently from the prediction of the Chapman ionization theory. The ionosphere is formed under the ionization effect of extreme ultraviolet (EUV) radiation and solar X-ray, and is influenced by solar winds and geomagnetic activity. In addition to this, the lower atmosphere contributes to the variability of the ionosphere (Anderson and Rowell, 1999; Prikryl et al., 2010). A variety of periodic and periodic variations could be observed in the ionosphere, which makes a serious impact on short wave communication, satellite communication and precise navigation with the Global Navigation Satellite System (GNSS), such as GPS (Liu et al., 2012). GNSS as one contemporary technique to detect the ionosphere has many merits including the high spatial- 
temporal resolution (the spatial resolution is smaller than $1^{\circ} \times 1^{\circ}$, and the temporal resolution is about 15 minutes), high station density (more than 400 IGS stations), good data quality and high precision (Hajj and Romans,1998; Kenpankho et al., 2011). With the rapid development of computerized ionospheric tomography (CIT), the total electronic content (TEC) of the largescale ionosphere can be estimated precisely in the three-dimensional space (Bernhardt et al., 1998). In the 1980s, researchers started to estimate TECs based on the media dispersivity using GPS dual-frequency data. In the past decades, much effort has been conducted to draw a more detailed picture of the climatology of the Earth's ionosphere, in terms of many kinds of observations on regional and global scale. But, because of its complexity still Space weather is a fairly new field in science today and has very interesting effects on humans, environment and technology in general. This time scientists are studying space weather strongly with a wide range of tools to try to learn more about the physical and chemical processes taking place in the upper atmosphere and beyond. One of the tools is Global Positioning System (GPS). It is a satellite based navigation radio system which is used to verify the position and time in space and on the Earth. Nowadays GPS allows to measure positions in real time with an accuracy of few centimeters (Warnant et al., 2007). GPS is a constellation of navigation satellites operated by US Department of Defense (DOD) and consists of at least 24 operational satellites, which are distributed in six orbital planes around the globe at an altitude of about $20,162.61 \mathrm{~km}$. The total signal for each satellite in GPS comprises of two transmission signals: the L1 signal having carrier frequency of 1575.42 MHz and the L2 signal of 1227.60 MHz (Daherty et al., 2002).

GPS satellites transmit signals through the ionosphere that exists at about $60-1500 \mathrm{~km}$ above the Earth's surface. The signals from the GPS satellites travel through the ionosphere on their way to receivers on the Earth's surface. The free electrons populating this region of the atmosphere affect the propagation of the signals, changing their velocity and direction of travel Due to the in homogeneity of the propagation medium in the ionosphere (Bardford and Spilker, 1996).

The total electron content along the GPS ray path from a satellite to a receiver is known as slant TEC (STEC). The STEC can be obtained from the difference between the pseudo ranges (P1 and P2) and the difference between the phases (L1 and L2) of the two GPS signals (Yizengaw et al., 2007).

$\mathrm{TEC}=\int_{\text {receiver }}^{\text {satellite }} \mathrm{Nds}$ 
Where $\mathrm{N}$ is the electron density; 1 TEC Unit $=1016$ electrons $/ \mathrm{m}^{2}$. TEC is obtained from the dual frequency code measurements using the relation (Bagiya et al., 2011).

$$
\begin{aligned}
& S T E C=\left[\frac{2}{K} \frac{f_{2}^{2} f_{1}^{2}}{f_{1}^{2}-f_{2}^{2}}\right]\left(P_{2}-P_{1}\right) \\
& S T E C=\left[\frac{2}{K} \frac{f_{2}^{2} f_{1}^{2}}{f_{1}^{2}-f_{2}^{2}}\right]\left(L_{1} \lambda_{1}-L_{2} \lambda_{2}\right)
\end{aligned}
$$

Where, f1 and f2 GPS signal frequencies and are equal to $1.57542 \mathrm{GHz}$ and $1.2276 \mathrm{GHz}$ respectively, and $\mathrm{K}=80.62 \mathrm{~m} 3 \mathrm{~s}-3$ is a constant that relates plasma frequency to electron density. Where, $\lambda 1$ and $\lambda 2$ are wavelengths corresponding to $f 1$ and $f 2$. The TEC measurements obtained from dual frequency GPS receivers are one of the most important methods of investigating the Earth's ionosphere. The ionosphere may be considered as a thin single layer surrounding the earth at a fixed height from the earth for which all the free electrons in the ionosphere are assumed to be concentrated in a single layer thin shell at the height of the main electron concentration in the ionosphere. In addition to that if we assume there are no lateral or horizontal electron density gradients, the vertical TEC (VTEC) can be simply mapped to the STEC as follows.

$$
\mathrm{STEC}=\frac{\mathrm{VTEC}}{\cos \aleph}
$$

Where $\boldsymbol{N}$ is the satellite zenith angle at the point of intersection of the line of sight with that of spherical single layer atmosphere Piercing point (Abdullah et al., 2009).

With the aim of global TEC variation, in this work diurnal, monthly and seasonal variations of ionospheric TEC over different latitude band and Correlation between IGS satellites ionospheric mean VTEC with Respect to COD satellites ionospheric mean VTEC data taken from 2008 has been measured.

\section{DATA ANALYSIS METHOD}

To study diurnal, monthly and seasonal variation of global ionospheric TEC and mean correlation of IGS VTEC with respect to COD VTEC, the globally processed and archived data taken from IGS and COD satellites has been gathered from world map TEC value available on web page ftp://lox.ucsd.edu/pub/rinex, ftp://garner.ucsd.edu/pub/rinex, and ftp://dataout.unavco.org/pub/rinex/obs for all days from January to December 2008. The already 
processed and archived data has been imported in to a MATLAB code. Using the MATLAB code diurnal VTEC variation for the Equinox and solstice days, monthly and seasonal variation has been plotted. Similarly the correlation between results obtained from IGS and COD satellites has been done.

\section{RESULTS AND DISCUSSION}

\subsection{Diurnal Variation of Ionospheric TEC}

To investigate diurnal variations of VTEC and Peak TEC value location, the researcher compared TEC variation for an interval of $4 \mathrm{~h}$ GMT for each day. And TEC variations for some equinox days have been compared with some solstice days with an interval of $4 \mathrm{~h}$ GMT.

On average, TEC in all of the selected equinox and solicits days of the year 2008, for every 4 hour intervals of each day is analyzed as follows. At $\mathrm{t}=0 \mathrm{hr}$ maximum TEC is stratified over south America, Hawaii island and Kiribati and small TEC value is recorded over South West Asia, Central and Eastern part of Africa and Indian ocean. 4 hrs later highest TEC value is recorded over Kiribati, South East Asia and smallest TEC is recorded over Africa. After 8 hrs maximum TEC value is recorded over south Asia and Indian Ocean leaving America and South Atlantic Ocean under darkness. After $12 \mathrm{hrs} \mathrm{highest} \mathrm{and} \mathrm{least} \mathrm{TEC} \mathrm{value} \mathrm{is} \mathrm{recorded} \mathrm{over} \mathrm{exactly}$ opposite to the event at $0 \mathrm{hr}$ time. At $\mathrm{t}=16 \mathrm{hr}$ TEC value is recorded Over exactly opposite to the event at $4 \mathrm{hr}$ time. At $\mathrm{t}=20 \mathrm{hr}$ TEC value is also recorded Over exactly opposite to the event at 8 hr time.

Out of the selected equinox and solstice days the maximum TEC value is recorded on March 20/2008. With a peak IGS \& COD TEC value of 42.9 \& 44.8 TECU respectively. Next to March least TEC value is recorded on September 22/2008 with IGS \& COD peak TEC value of $32.3 \&$ 31.4 TECU respectively. On the contrary, the least peak ionospheric TEC value is recorded on June 21/2008 with a peak IGS \& COD TEC value of $28.3 \& 27.2$ TECU respectively. The diurnal variation of ionospheric TEC during December 21/2008 is also stratified moderate peak TEC value with IGS peak TEC value of 29.9 TECU and COD peak TEC value of 34.8TECU. Therefore, the results of figure 1 to 8 reviled that almost all of the data observed through COD satellite is similar with the data taken from IGS satellite in all the equinox and solstice days at the year of 2008 . 


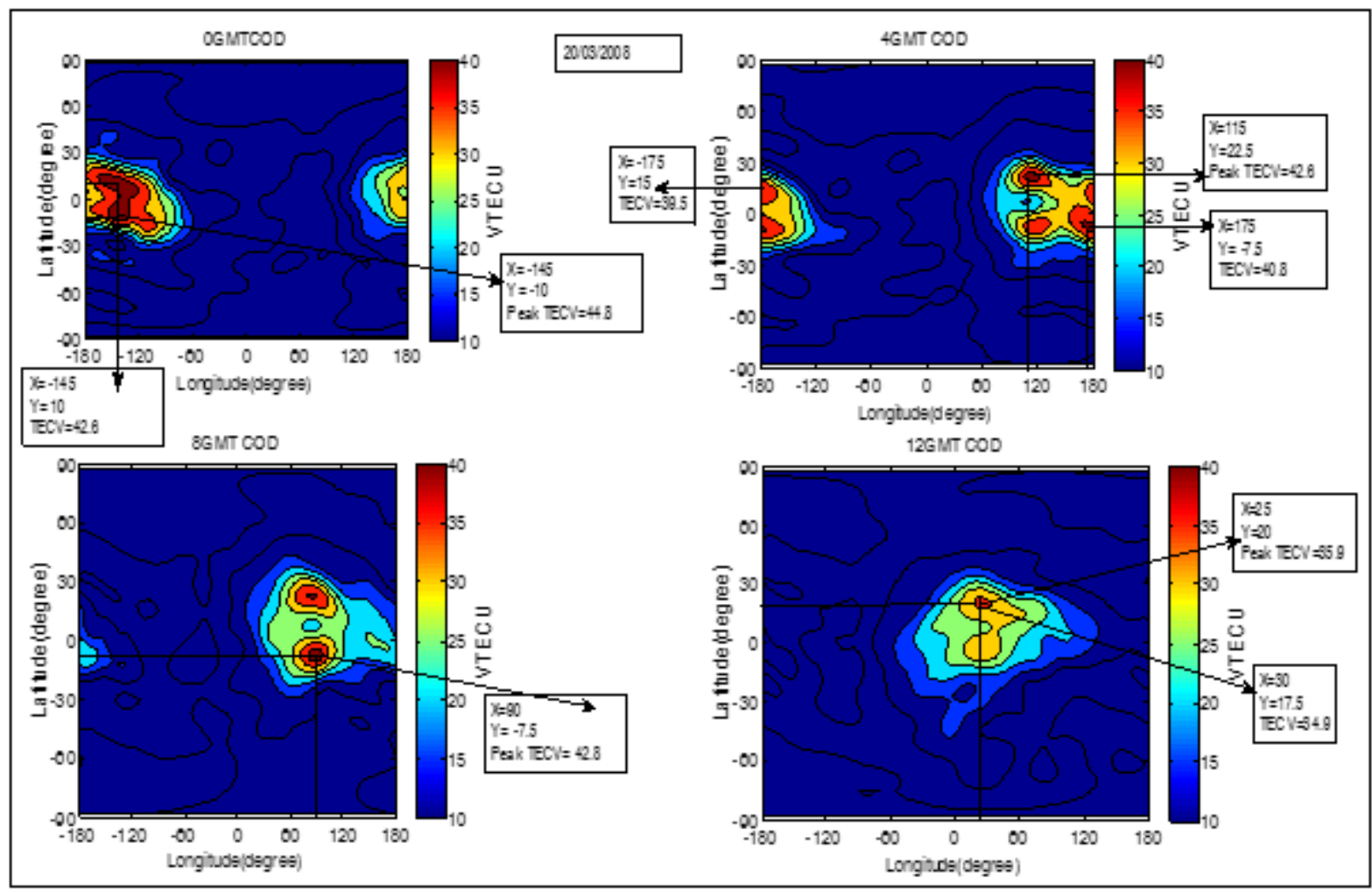

Figure 1. Diurnal variations of ionospheric TEC, March 20, 2008 Data taken from IGS satellite.

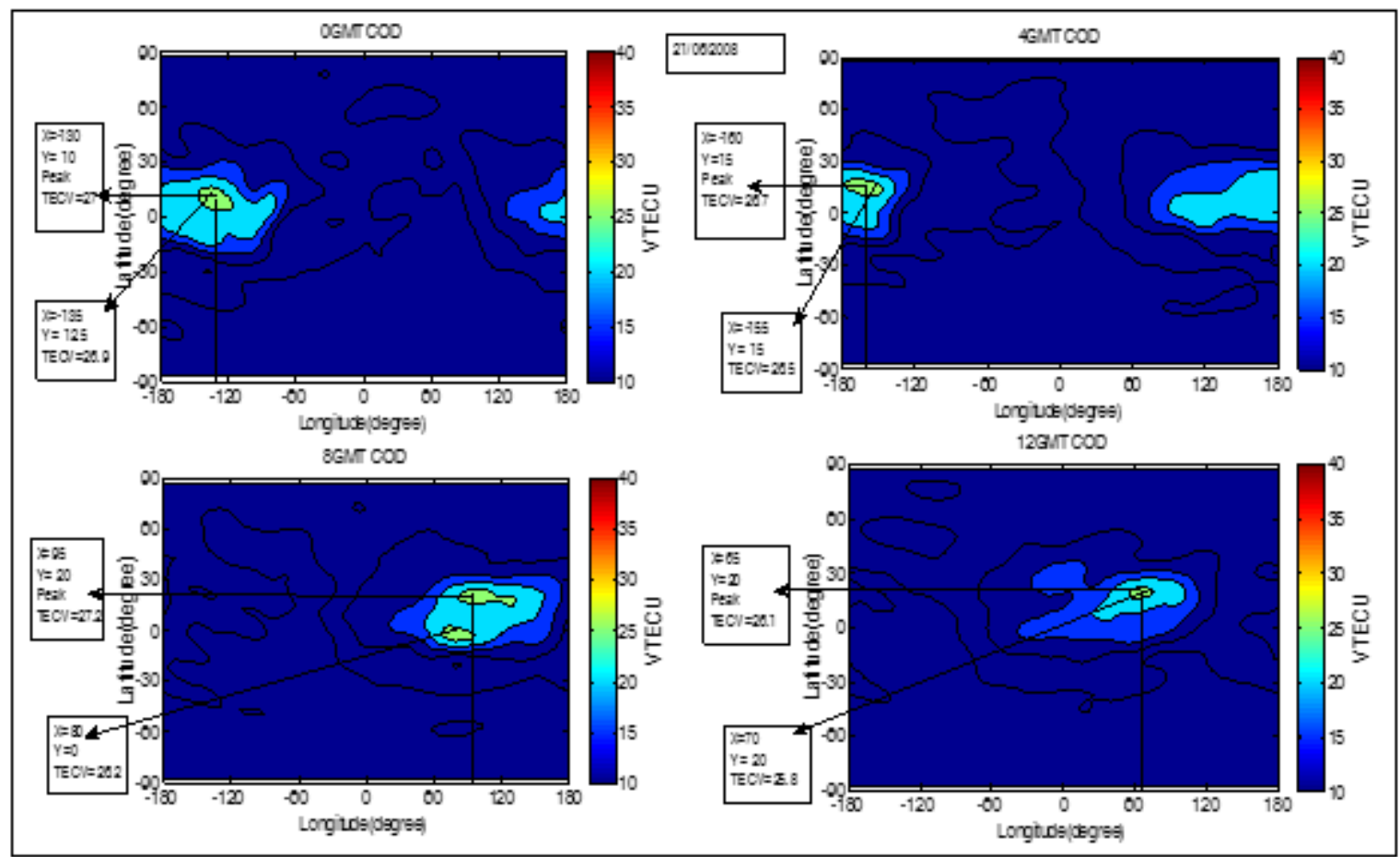

Figure 2. Diurnal variations of ionospheric TEC, March 20, 2008 Data taken from COD satellite. 


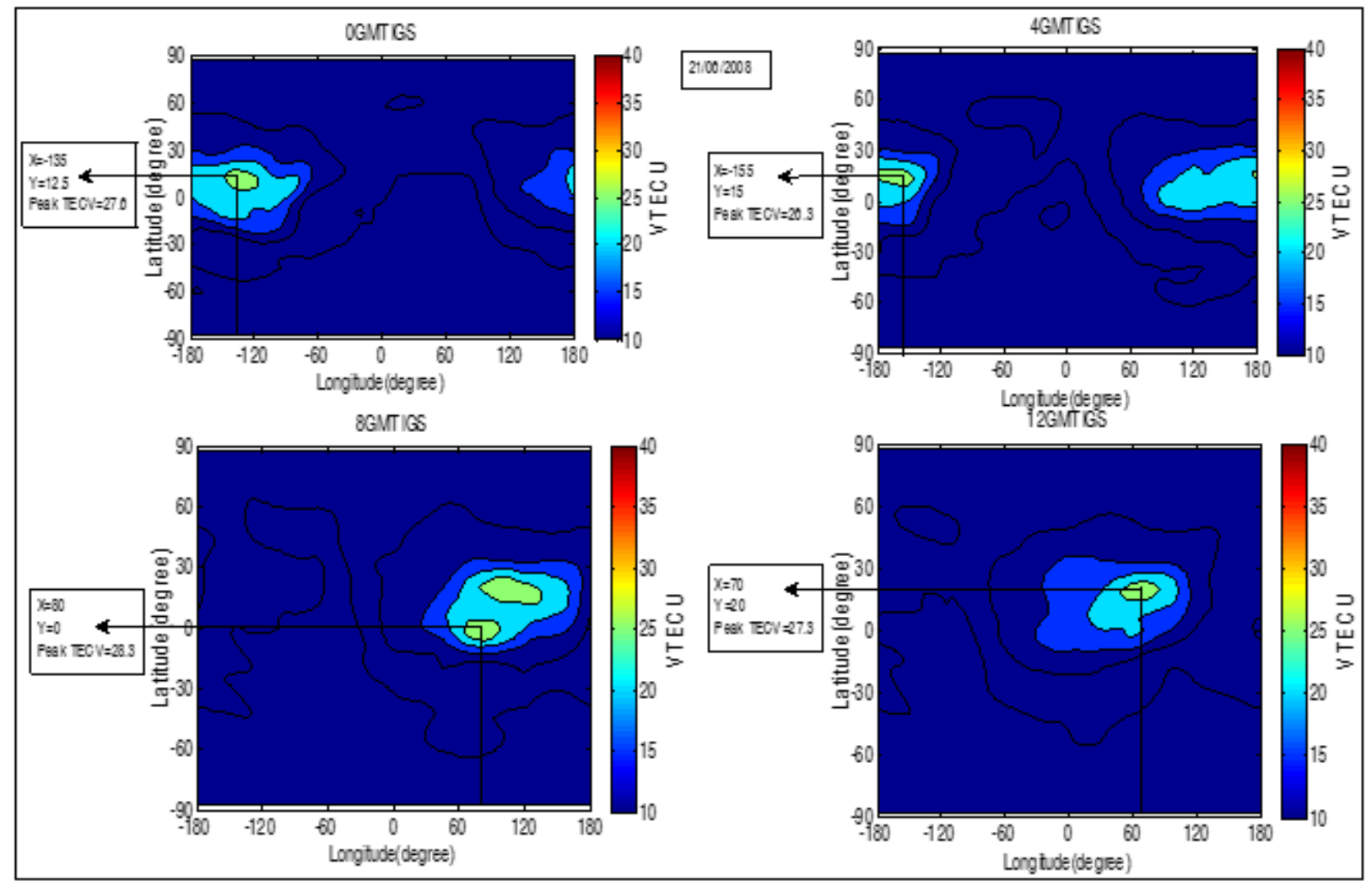

Figure 3. Diurnal variations of ionospheric TEC on June 21/2008 Data taken from IGS satellite.

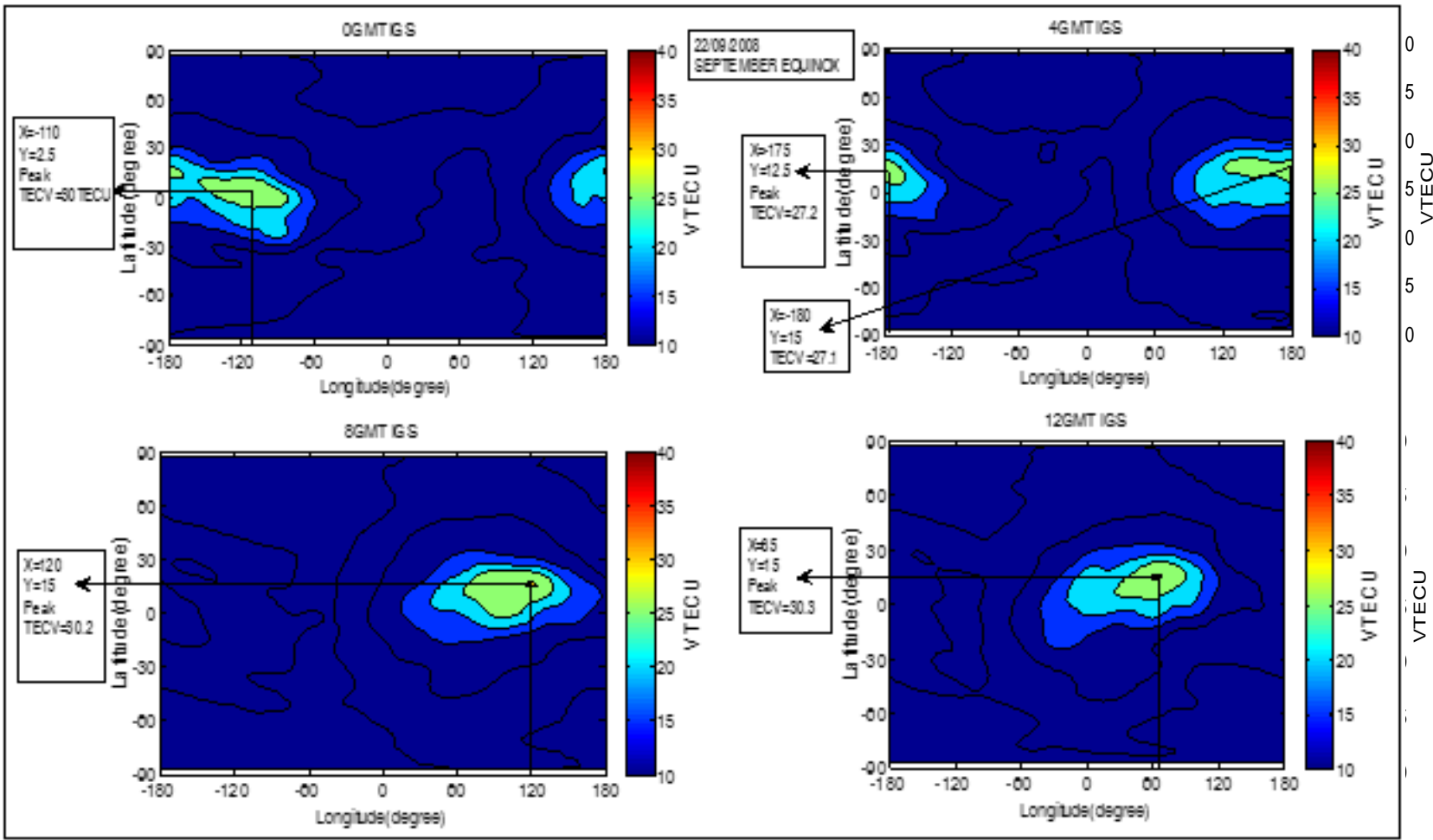

Figure 4. Diurnal variations of ionospheric TEC, June 21/2008 Data taken from COD satellite. 


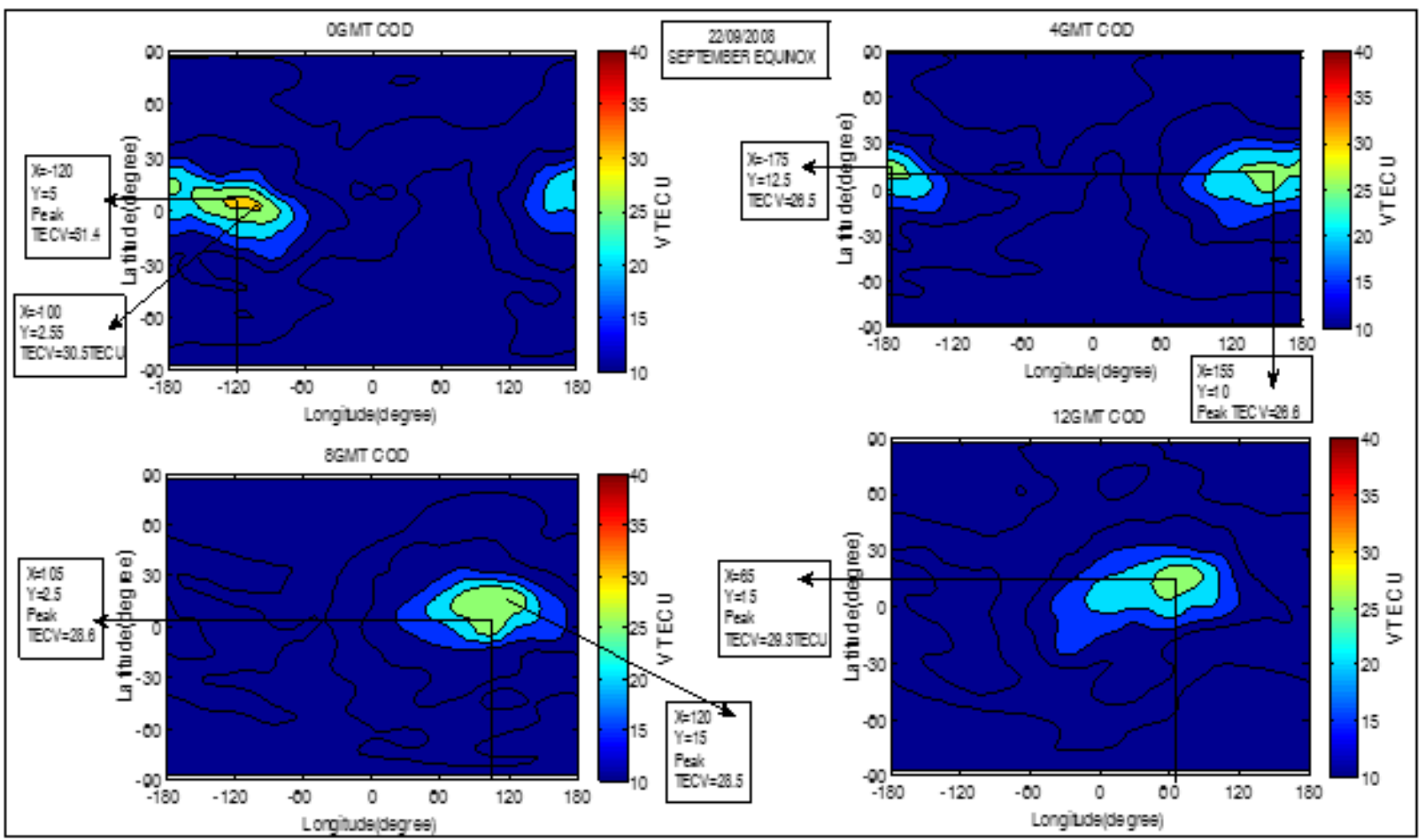

Figure 5. Diurnal TEC variations of a day September 22/2008 Data taken from IGS satellite.

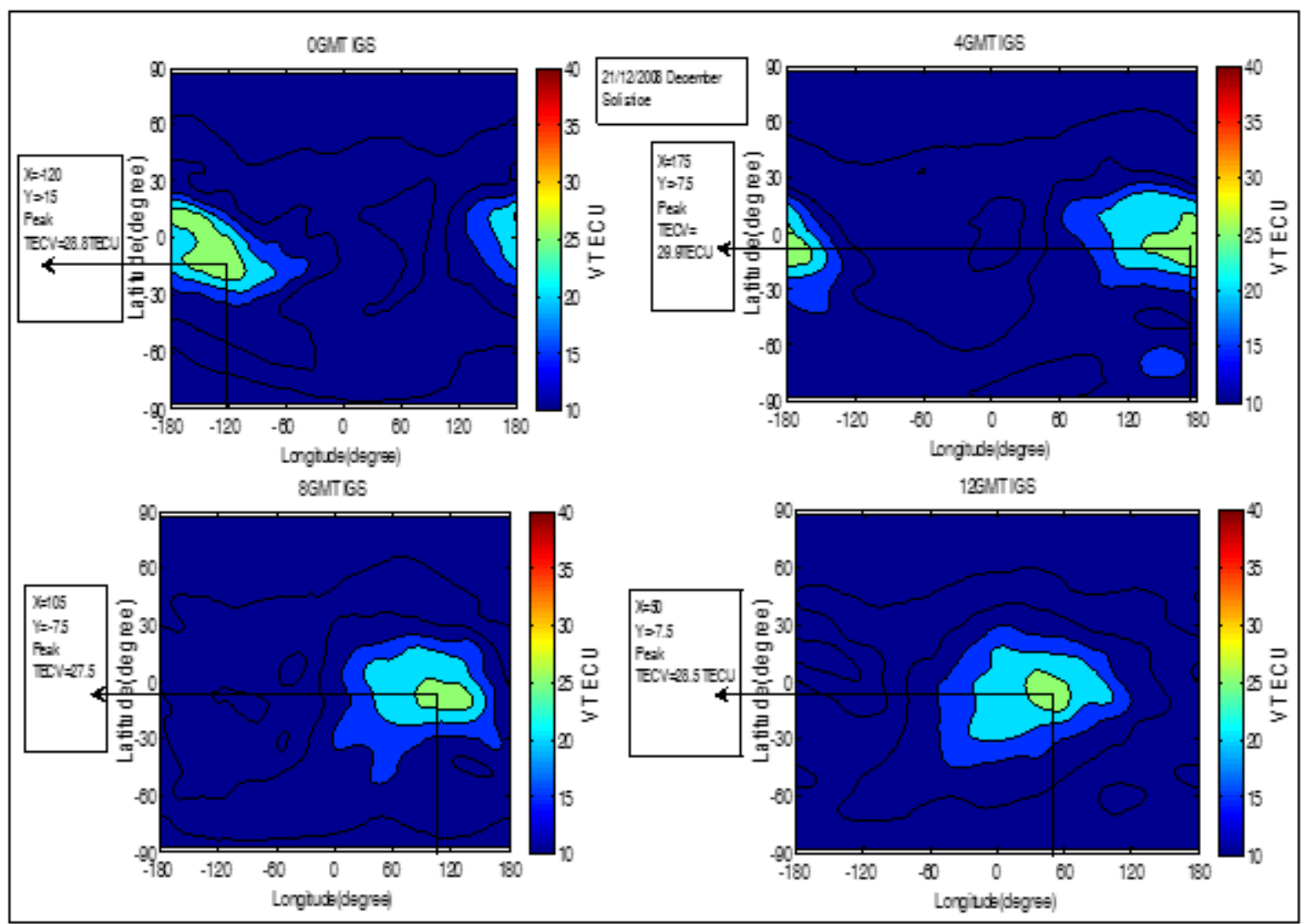

Figure 6. Diurnal TEC variations of a day September 22/2008 Data taken from COD satellite. 


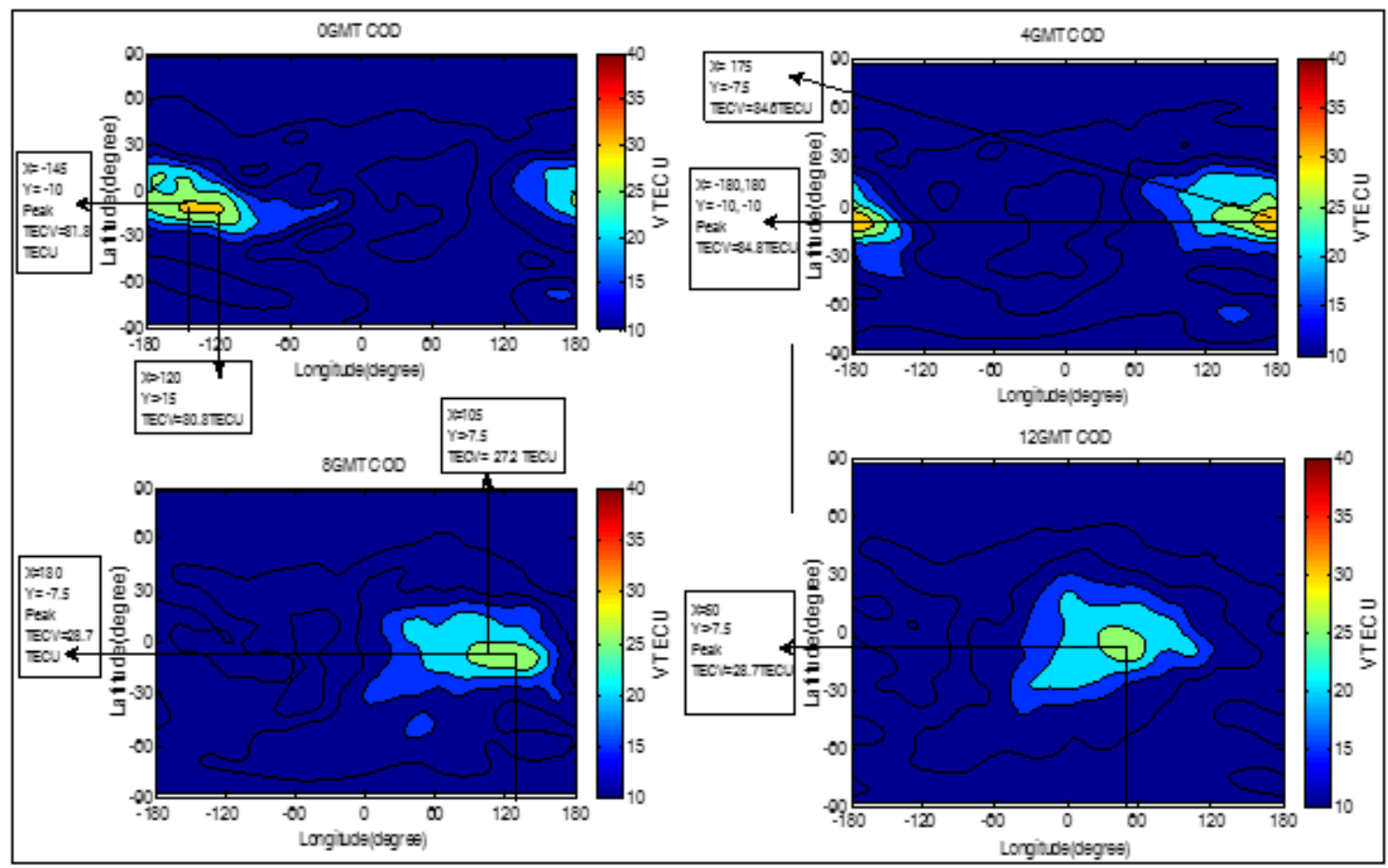

Figure 7. Diurnal TEC variations of a day December 21/2008 Data taken from IGS satellite.

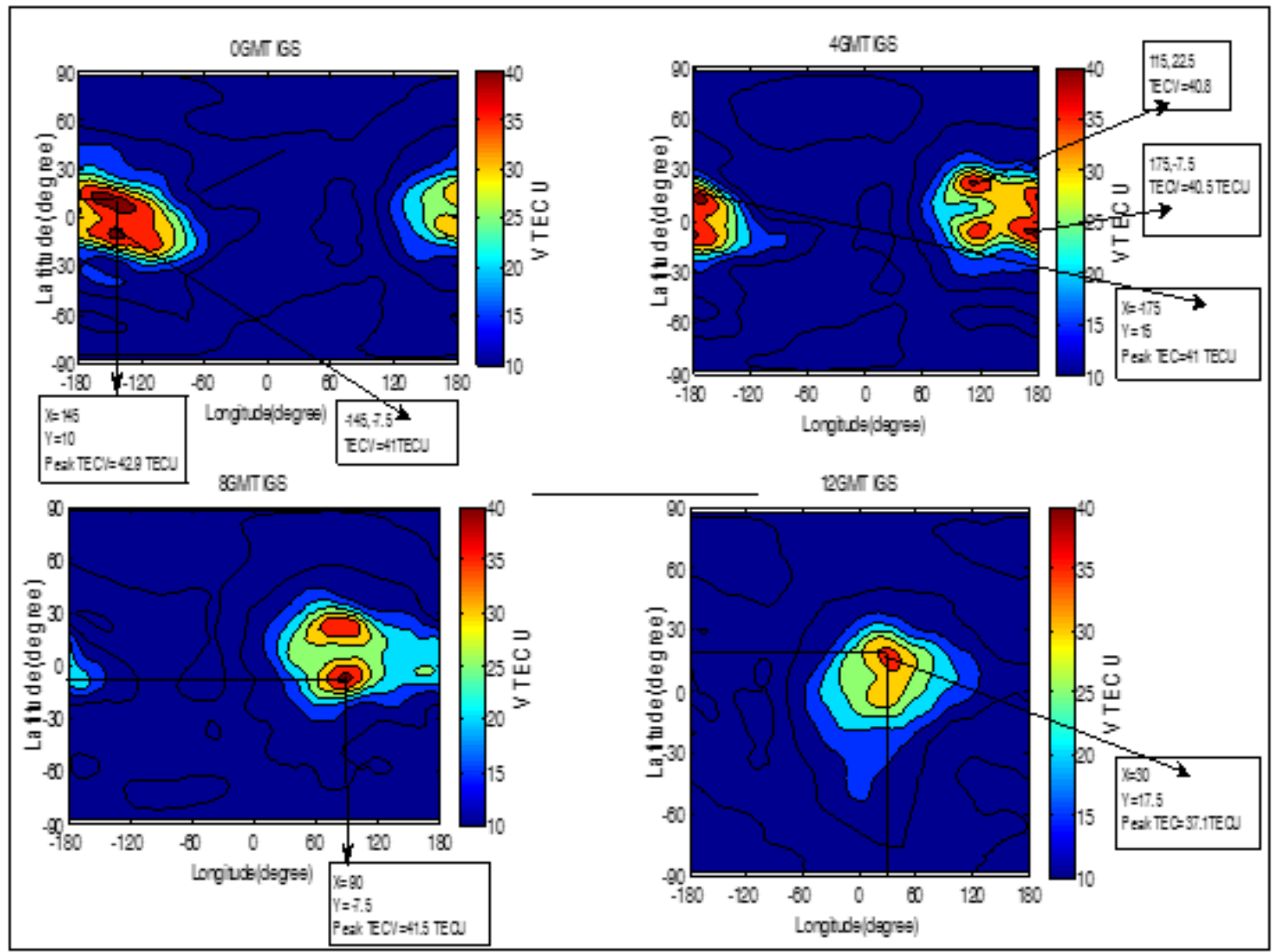

Figure 8. Diurnal TEC variations of a day December 21/2008 Data taken from COD satellite. 
The result also shows that even if the peak TEC value is vary from hour to hour or from day to day, noon hour TEC is synchronously moving westward in all the selected equinox and solstice days. the results of the two satellites also shows that ionospheric TEC is Maximum at noon time, at the time where the sun is overhead and ionization is Maximum in all days of the year due to the radiated light rays on the day side but TEC is Minimum on the night side due to recombination.

\subsection{Monthly Variation of Ionospheric TEC}

Global monthly variation of TEC for 12 months of 2008 is shown in figures 9 and 10. Data is taken from IGS and COD satellites in low, middle and high-latitudinal regions.

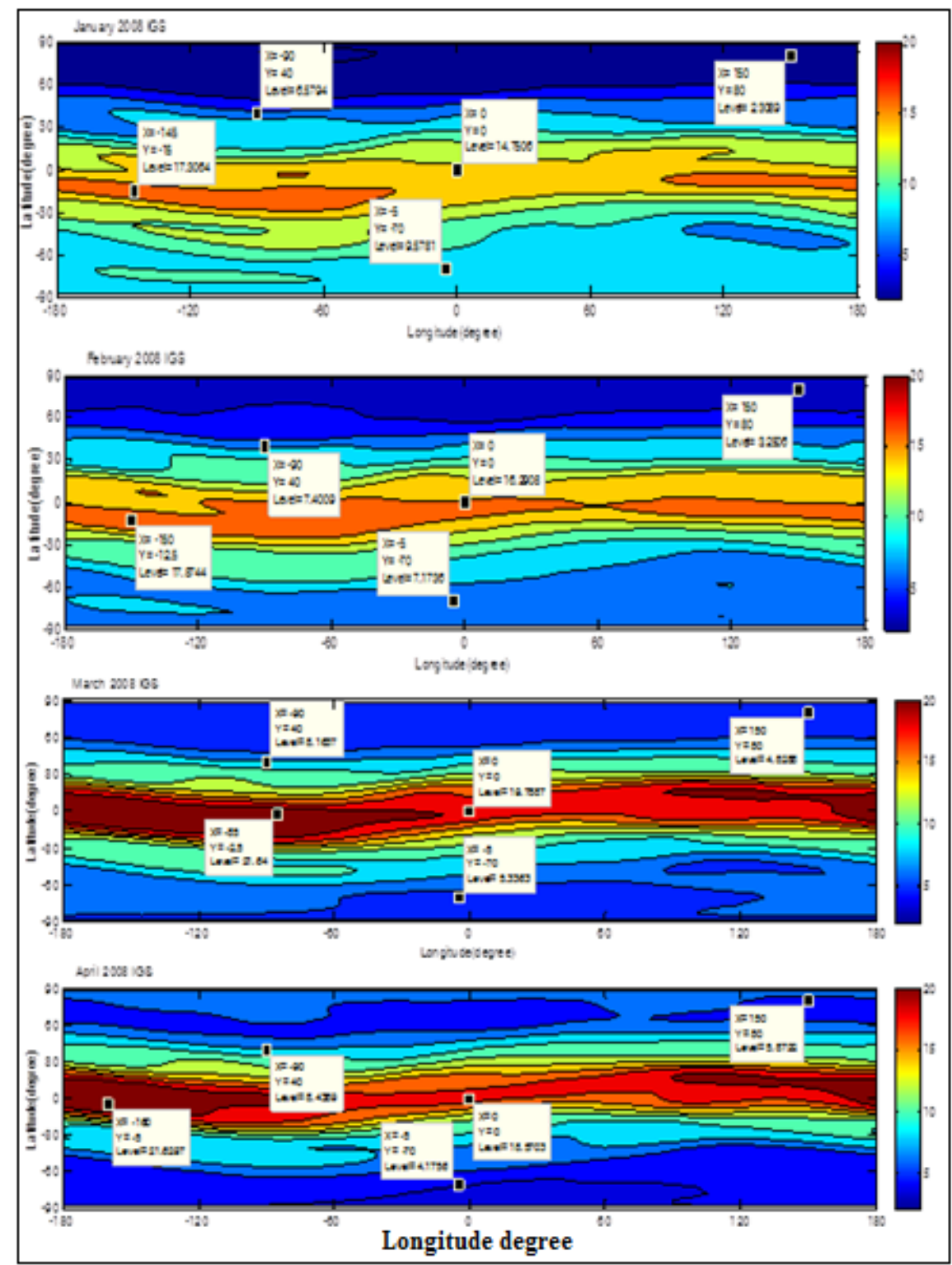

Figure 9. Monthly variation of Ionospheric TEC for the year 2008, data taken from IGS satellite. 


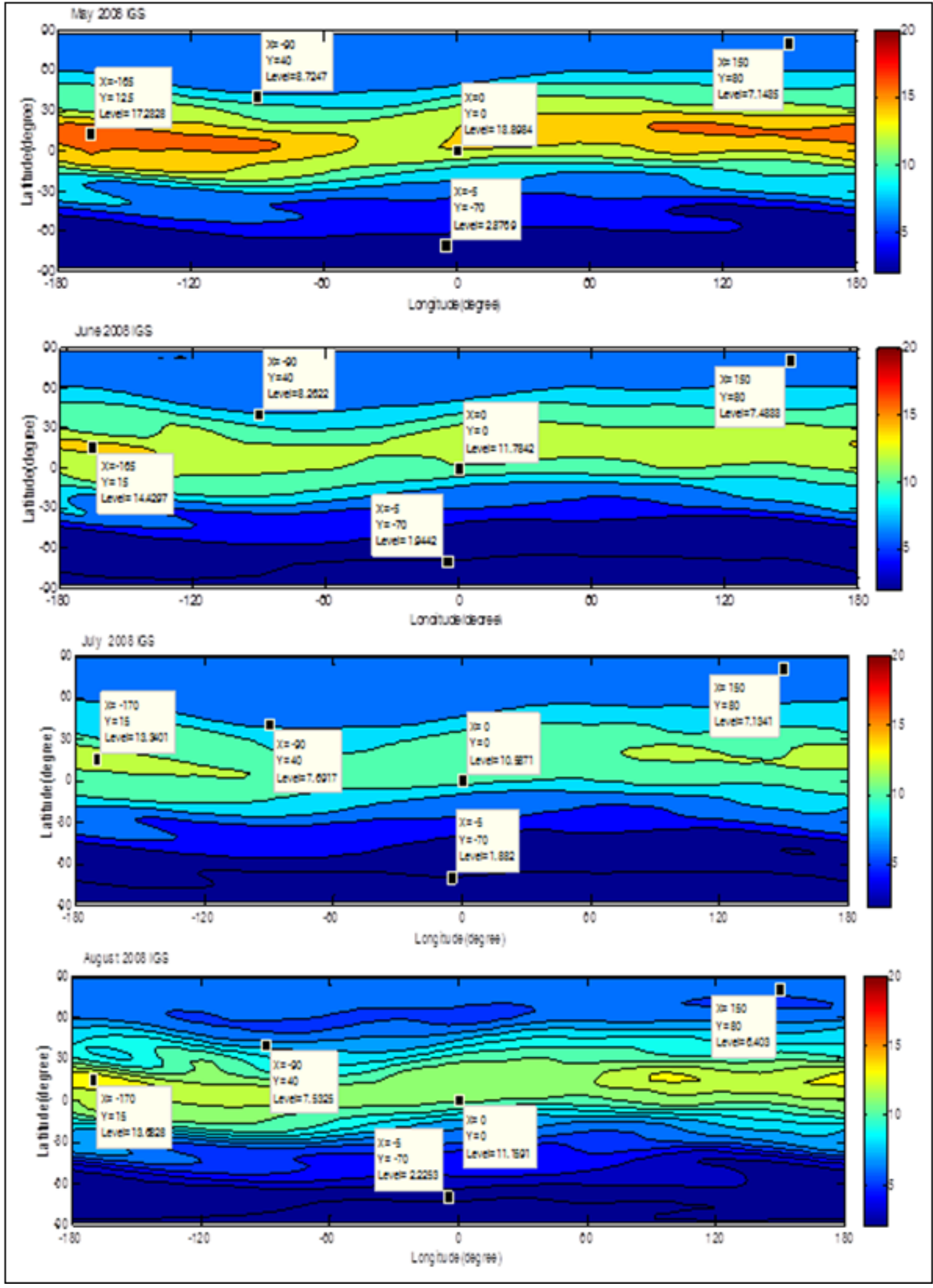

Figure 9 (continue..). 


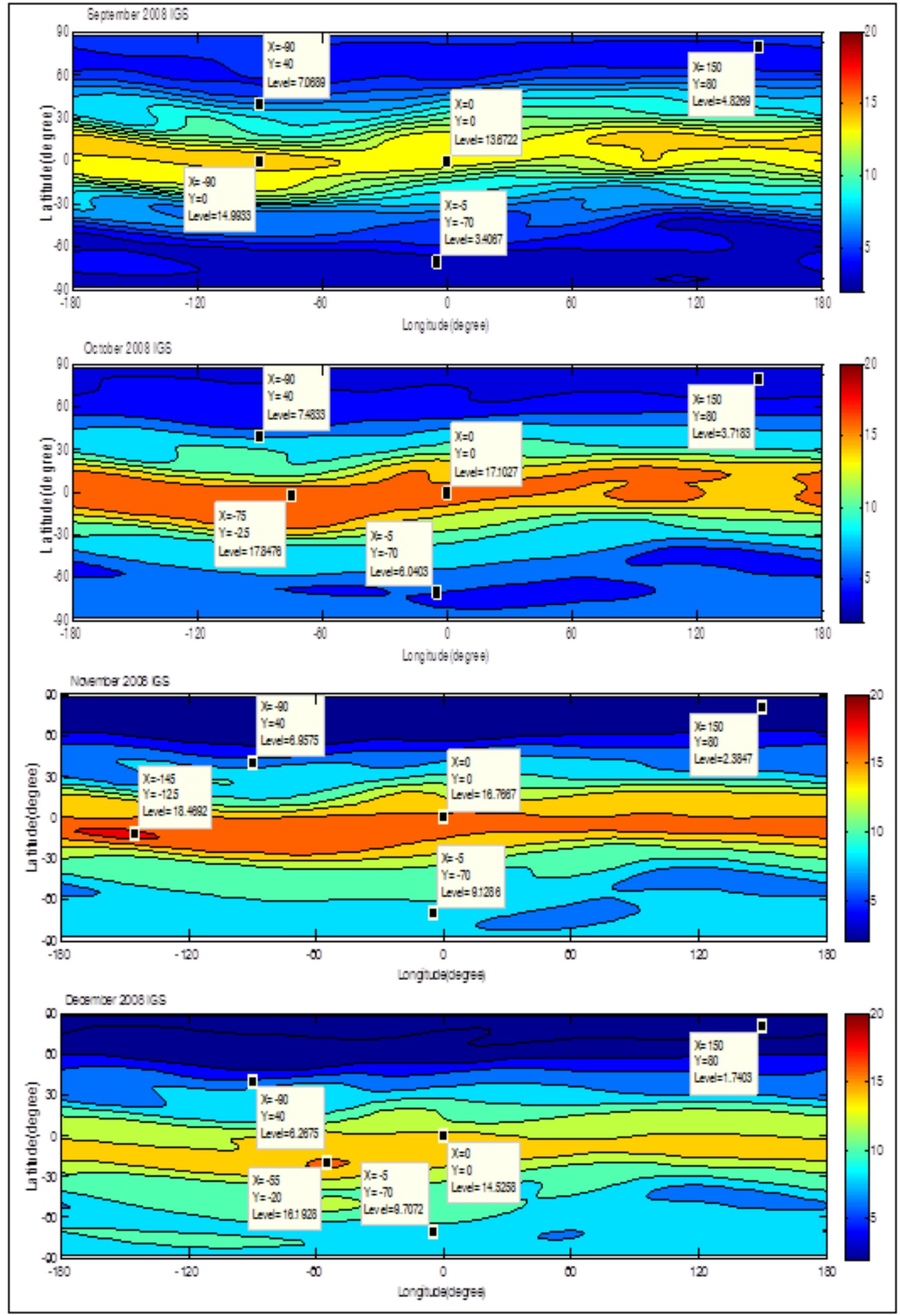

Figure 9 (continue...). 


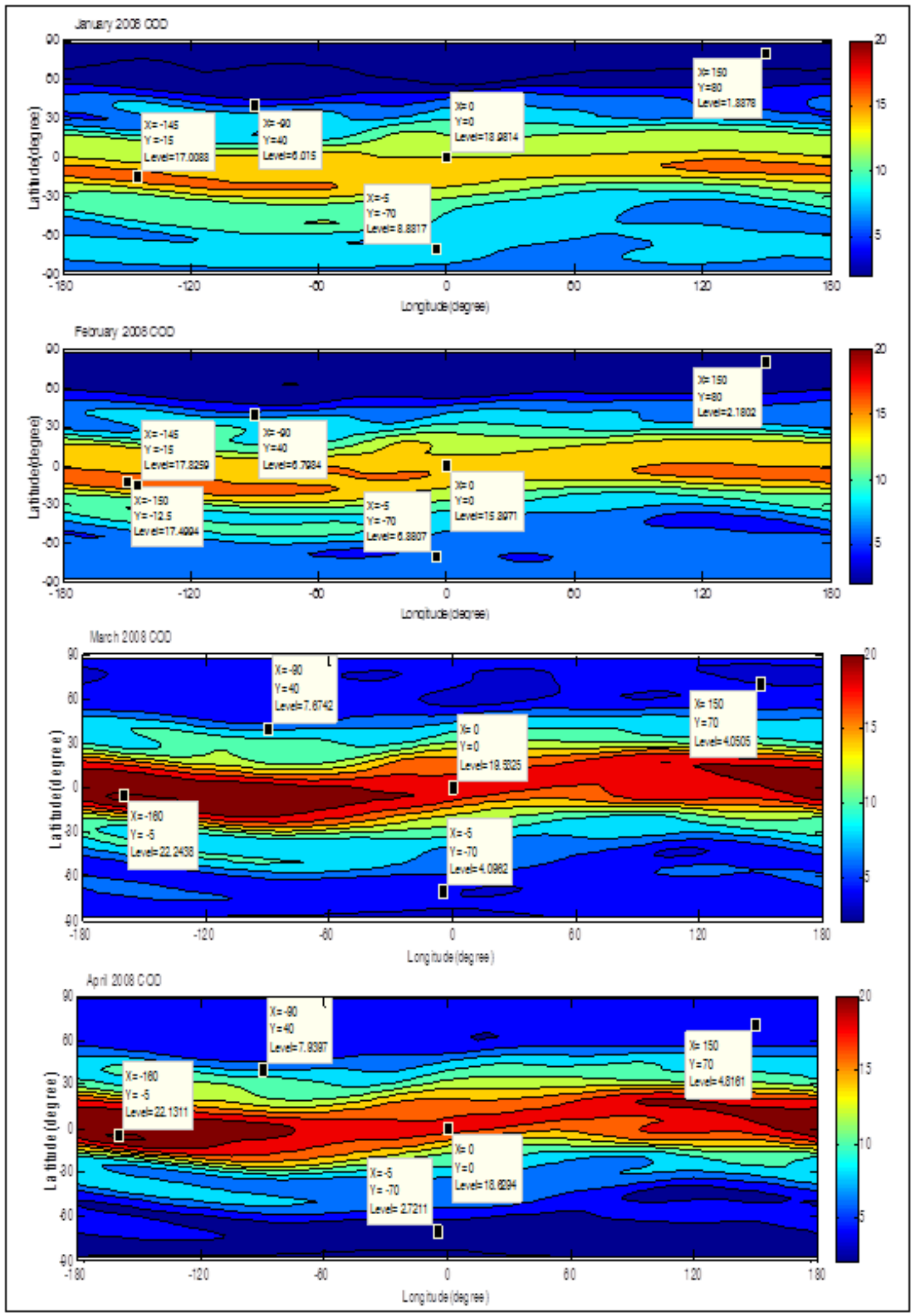

Figure 10. Monthly variation of Ionospheric TEC for year 2008, data taken from COD satellite. 


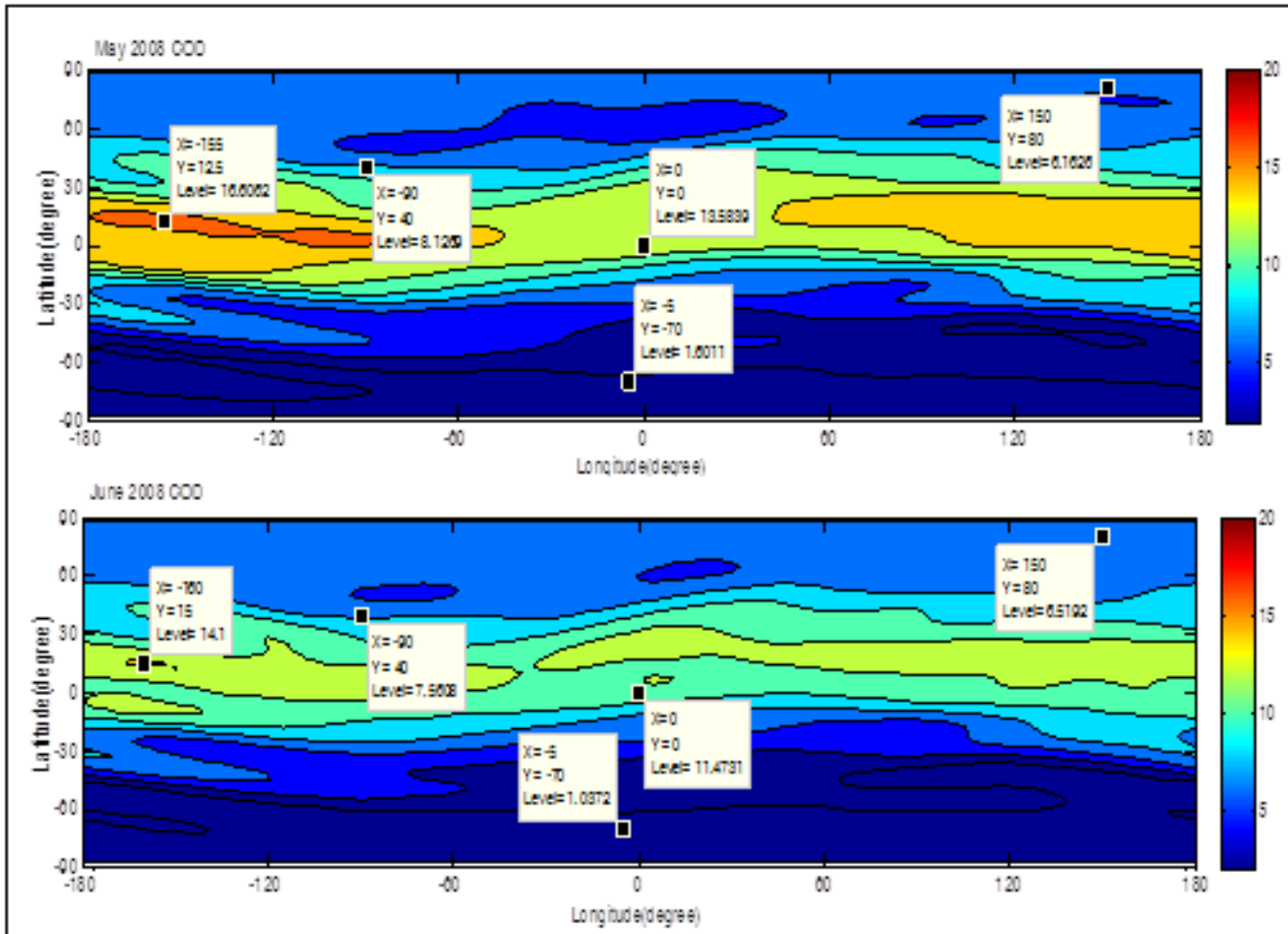

July 2000000
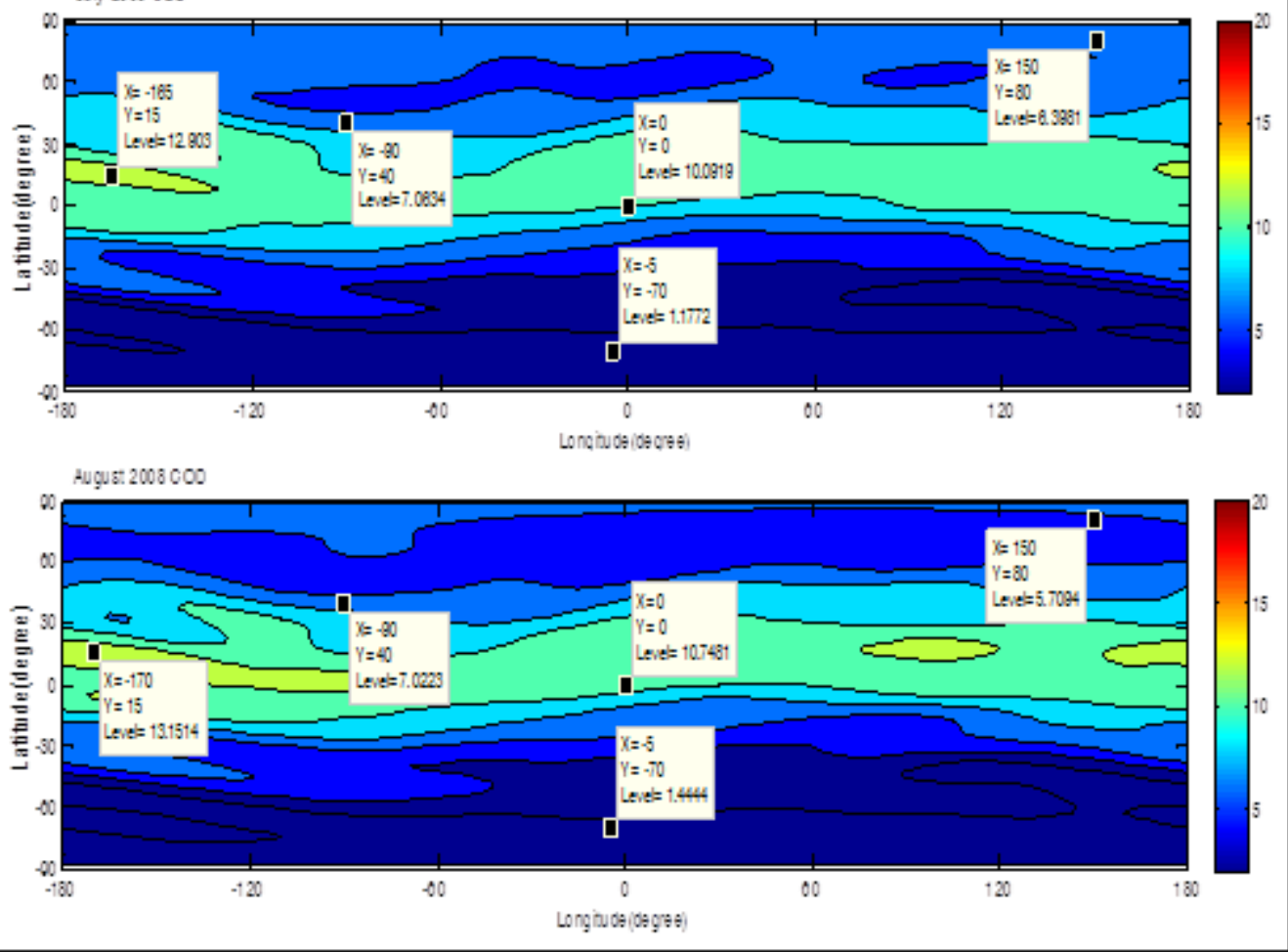

Figure 10 (continue..). 


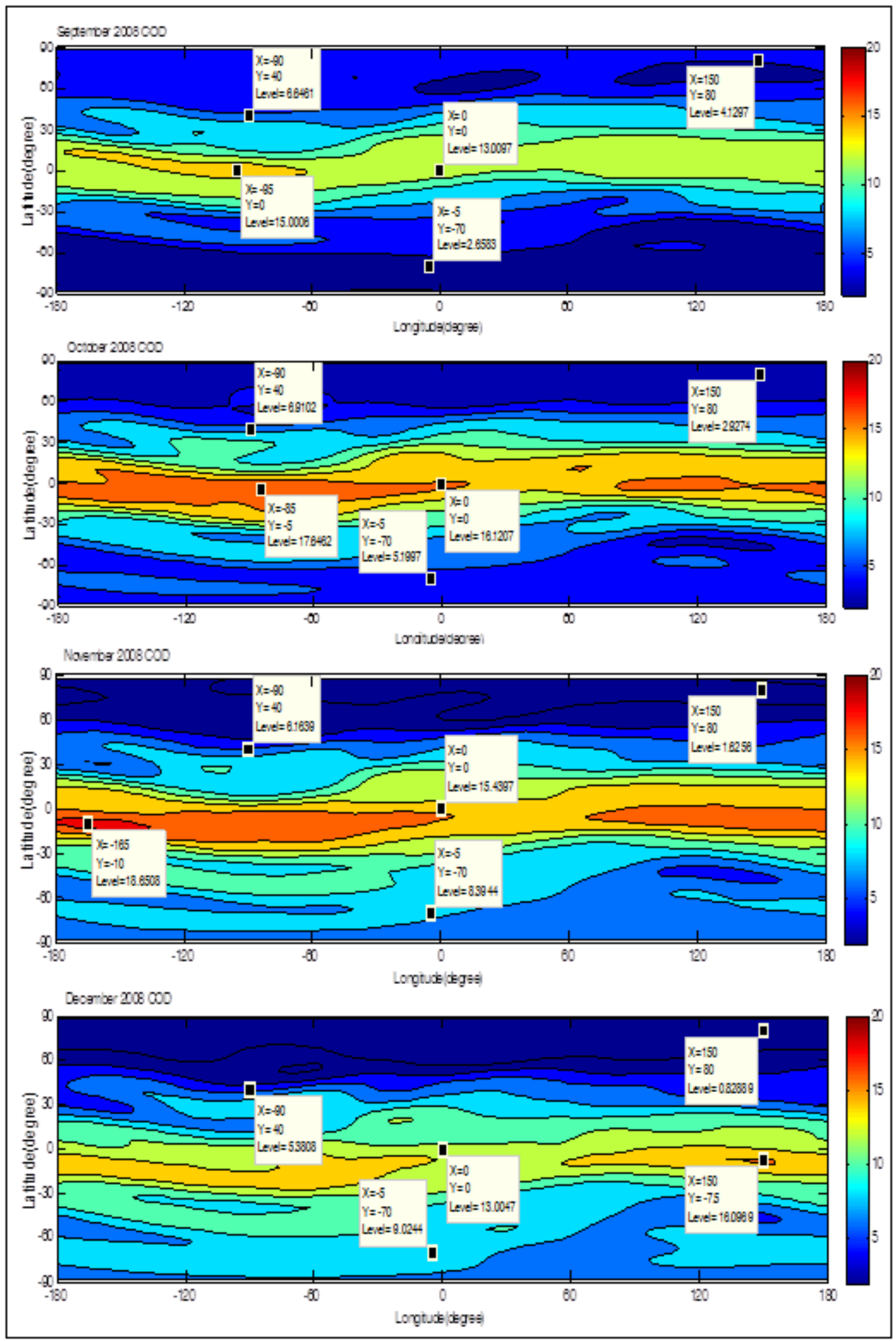

Figure 10 (continue..). 
Results of IGS satellites in figure 9 revealed that the monthly mean TEC variations recorded on March is highest, which valued 21.64TECu, observed over south America and Kiribati, and July recorded the least peak TEC value 13.3 TECu over North western Equator Hawaii islands.

Results of COD satellites also revealed that the monthly mean TEC variations recorded on March is highest: which valued 22.24TECU, observed over south west equator Kiribati and south American regions, On the contrary, July recorded the least peak TEC 12.9TECu over North western Equator Hawaii islands (US).

On average results of the two satellites reviled that, March, April, October and, November recorded highest mean TEC values ranging from 17.64 -22.24 TECu. June, July and August recorded minimum mean TEC values ranging from 12.9 - 14.4 TECu. But, January, February, May, September and December recorded moderate mean TEC value, ranging from 15 - 17.8 TECu.

At large, almost all of the data observed through COD satellite is similar with the data taken from IGS satellite at the year of 2008. The observations of the two satellites also show that the mean TEC presents stronger solar activity sensitivity at lower-latitude bands than the middle and high latitudes.

The day-to-day or month-to-month variability in TEC, which has also been observed by some authors, may be due to the changes in the activity of the sun and the changes in the intensity of the incoming radiations and the zenith angle at which they are incident on the Earth's atmosphere. EEJ strength, Earth's magnetic field and the dynamics of the neutral wind are also some factors which may be responsible for this variability. The results of variation in mean TEC over the low, middle and high-latitudes considered in this work showed that the variation in mean TEC is dependent on season, latitude and local time of occurrence (Rama Rao et al., 2006).

\subsection{Seasonal variation of Ionospheric TEC}

From IGS satellites observation maximum TEC is recorded during E season/ 18.68 TECU observed over South American regions and Kiribati. And least TEC is recorded on J season 14.6 TECu, over the same region. results from COD satellites also reviled that the highest seasonal mean TEC is stratified in E season 18.71TECU, observed over south west equator Kiribati and South American regions, and lowest peak TEC value is recorded on J season 14.16TECu over the same region. 


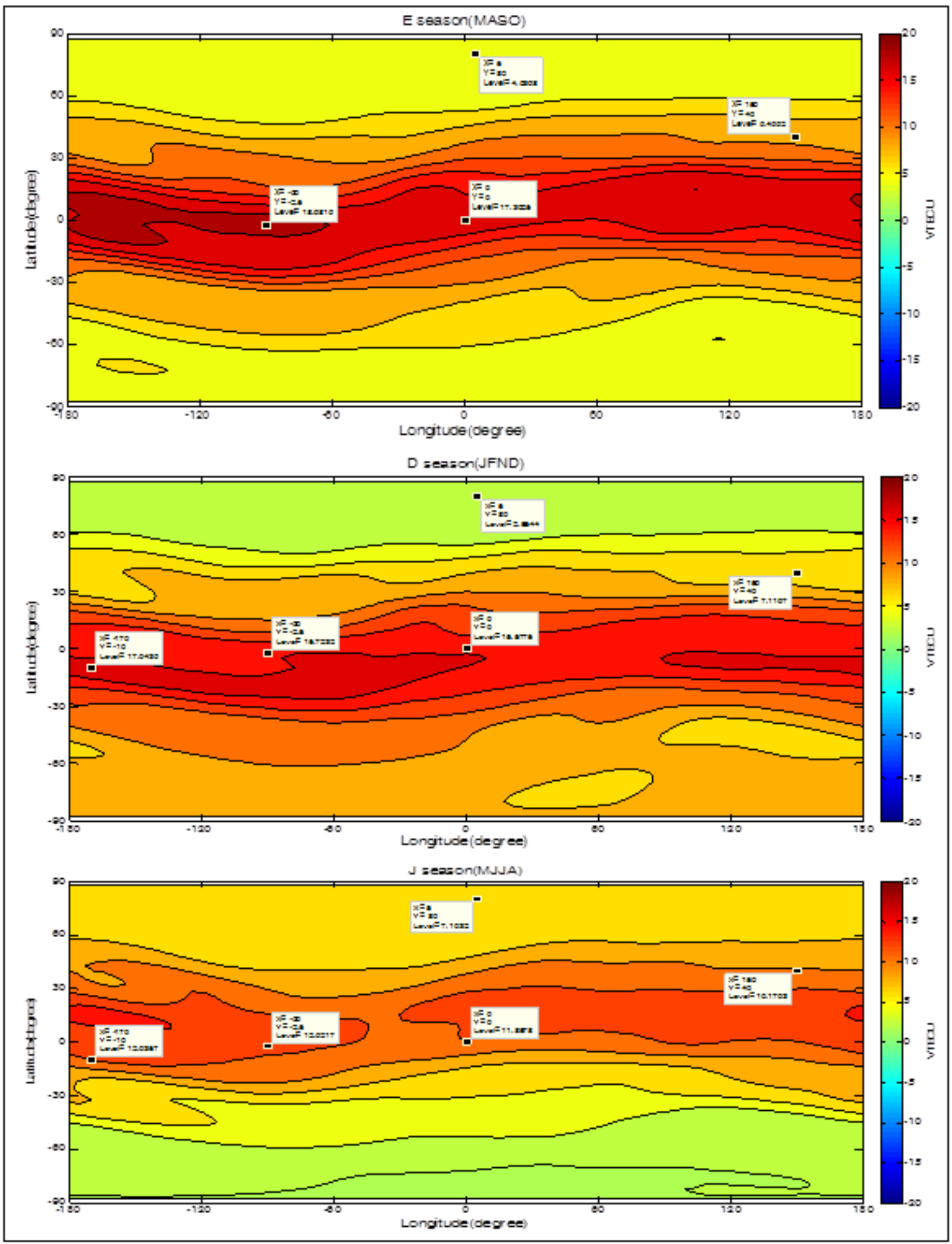

Figure 11. Contour plots of seasonal mean TEC variation, data taken from IGS satellite. 


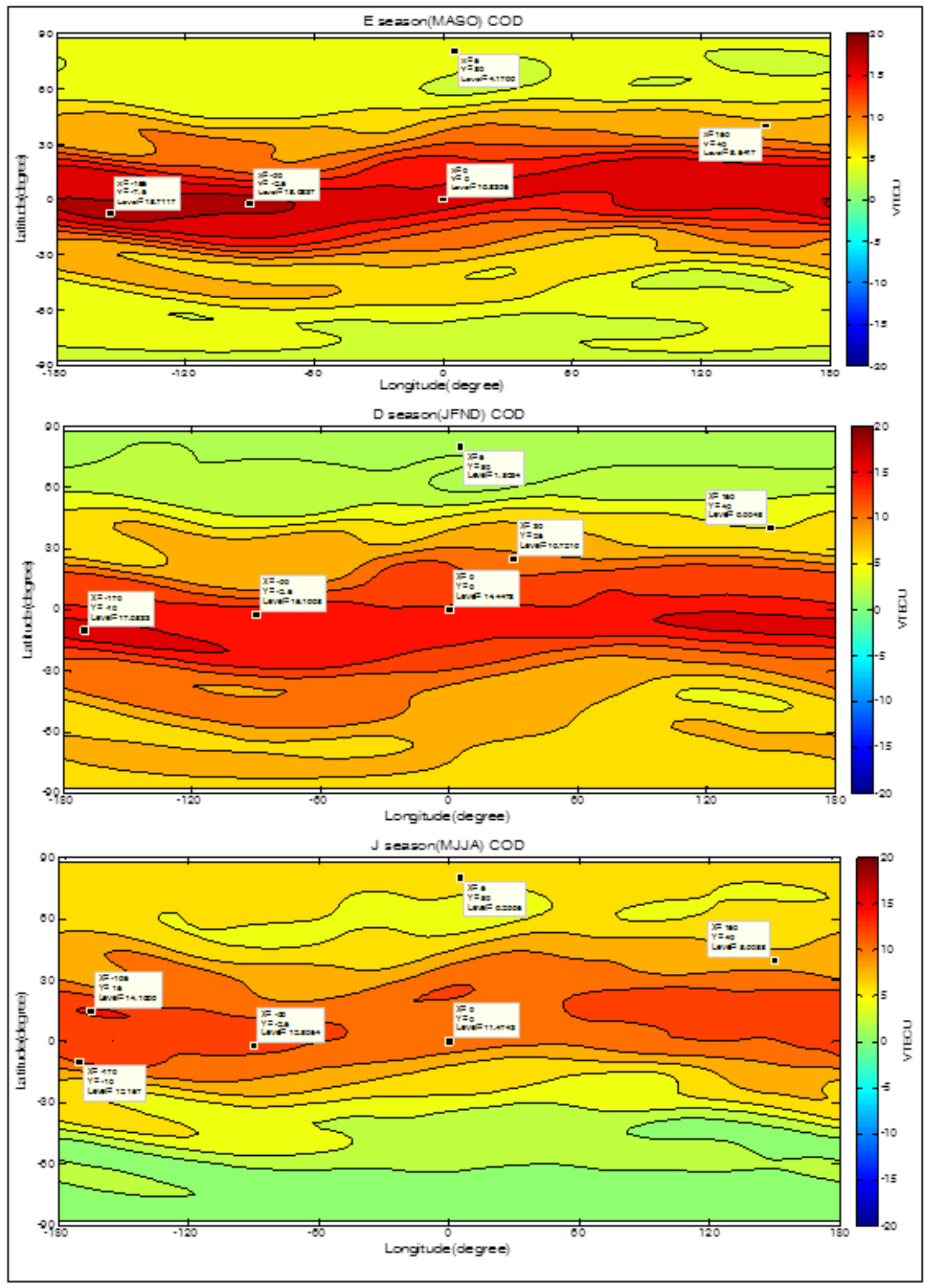

Figure 12. Contour plots of seasonal mean TEC variation, data taken from COD satellite. 
Therefore, as it can be seen from the contour graphs in figures 11 and 12, in all of the three seasons the data observed by the IGS satellites is similar with the data observed by the COD satellites. And by the help of those two international GPS satellites the peak TEC value for each season is observed at the same place.

Warnant et al. (2007) suggested that seasonal changes result from changes in ratio of the concentration of atomic oxygen and molecular nitrogen in the F-region. During the daytime, the equator is hotter than the pole, therefore meridional wind flows towards the pole from the equator. This flow of meridional wind changes the neutral composition and $\mathrm{O} / \mathrm{N} 2$ decreases at equatorial and low latitude stations. The decrease is maxima in equinoctial months. At $350 \mathrm{~km}$ altitude (F2-layer), N2 dissociation is the major process which removes ambient electrons. Hence, the decrease in $\mathrm{O} / \mathrm{N} 2$ ratio will result in higher electron density and therefore in equinox TEC is highest (Reshbeth and Setty, 1961).

\subsection{Mean Correlation of IGS VTEC With Respect To COD VTEC}

Figure 13 shows the correlation between Mean TEC values recorded by IGS satellite with the mean TEC values recorded by COD satellite by the year of 2008. The correlation coefficient for this relation is $r \geq 0.9$ in $\mathrm{b} / \mathrm{n}$ (0.8 to 1.00). According to the criterion (Best et al., 1991), the correlation for this relation shows very high.

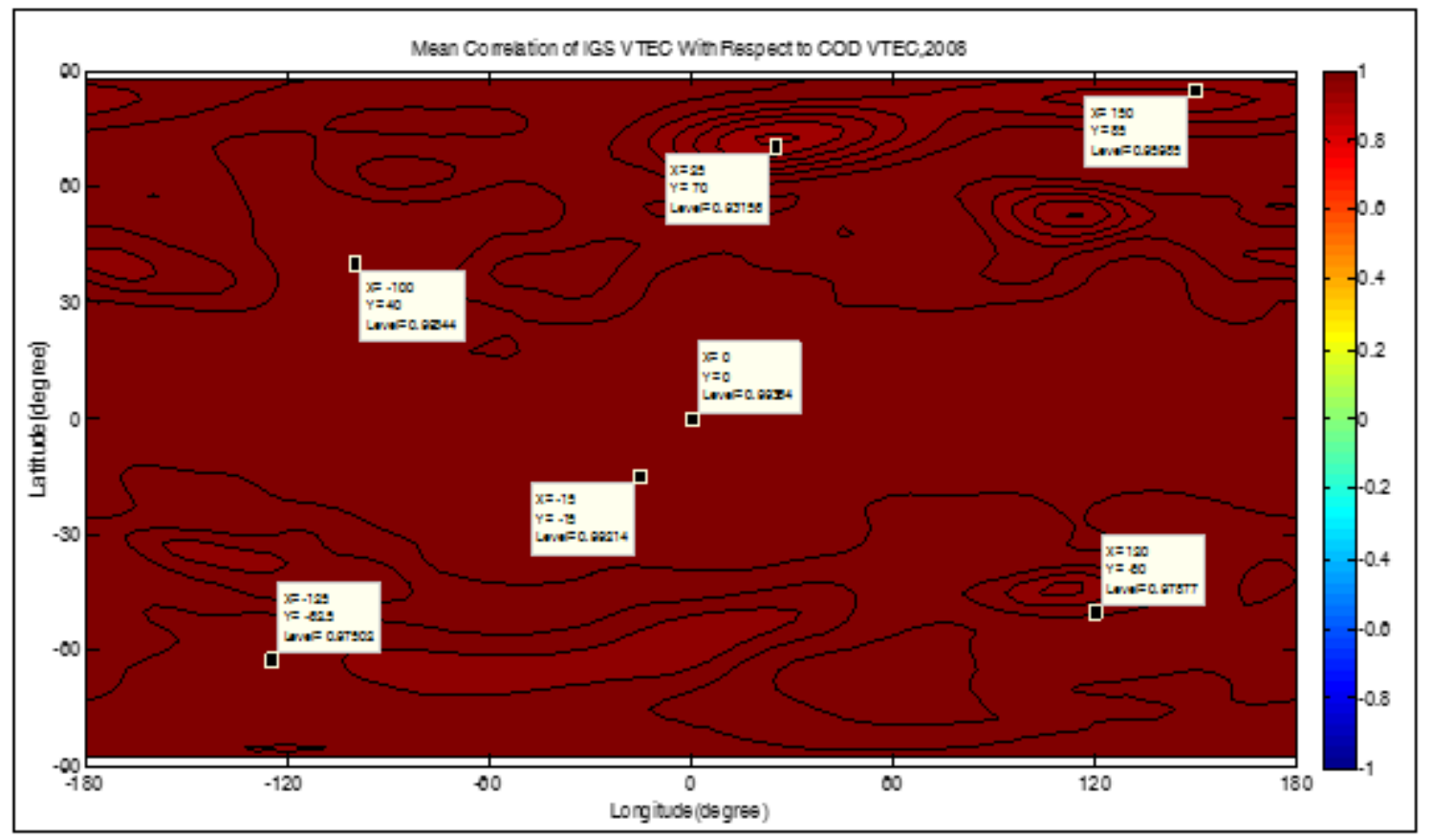

Figure 13. Mean Correlation of IGS VTEC With respect to COD VTEC. 
The results of this analysis found that there is very high correlation between Mean TEC values recorded by IGS satellite with the mean TEC values recorded by COD satellite by the year of 2008 in all law, middle and high latitudes. For example as can be seen in figure 13 the correlation between TEC values of the two satellites at law, middle and high latitudes respectively is given as follows. at law latitude [ $\left(0^{\circ}\right.$ latitude, $0^{\circ}$ longitude, $\left.\mathrm{r}=0.99\right),\left(15^{\circ} \mathrm{S}, 15^{\circ} \mathrm{W}\right.$ $\mathrm{r}=0.992)]$, at middle latitude $\left[\left(40^{\circ} \mathrm{N}, 100^{\circ} \mathrm{W}, \mathrm{r}=0.99\right),\left(50^{\circ} \mathrm{S}, 120^{\circ} \mathrm{E} \mathrm{r}=0.978\right)\right]$, at high latitude $\left[\left(85^{\circ} \mathrm{N}, 150^{\circ} \mathrm{E}, \mathrm{r}=0.96\right),\left(70^{\circ} \mathrm{N}, 25^{\circ} \mathrm{E} \mathrm{r}=0.931\right)\right]$ According to those results the TEC value recorded by the two satellites At every corner of the world is highly correlated and shows that the data taken from the two satellites was equivalent.

\section{CONCLUSION AND RECOMMENDATION}

The results of this study show that in both IGS and COD observations out of the selected equinox and solstice day's maximum value of TEC is recorded on March 20/2008 due to the maximum solar radiation reaching to the ionosphere of the Earth. And minimum peak ionospheric TEC value is recorded on June 21/2008 due to emission of low solar radiation. Even though the peak TEC value is varied from hour to hour or from day to day, noon hour TEC is synchronously moving westward in all the selected equinox and solstice days.

Results from IGS and COD satellites also illustrated that highest monthly mean TEC value is recorded on March and highest seasonal mean TEC value is recorded during E-season. However, the least monthly mean TEC value is recorded on July and smallest seasonal mean TEC value is recorded during $\mathrm{J}$-season.

The results of the two satellites show that ionospheric TEC is Maximum at noon time, at the time where the sun is overhead due to the radiated light rays on the day side but TEC is Minimum on the night side due to recombination. The mean TEC presents stronger solar activity sensitivity at lower-latitude bands than the middle and high latitudes.

From the results of this analysis it is found that there is very high correlation $(r \geq 0.9)$ between Mean TEC values recorded by IGS satellite with the mean TEC values recorded by COD satellite by the year of 2008 in all low, middle and high latitudes. Such and related studies should be conduct continuously because it helps to know and maintain the local and global variations of weather and climate situations. 


\section{ACKNOWLEDGEMENTS}

The authors would like to thank to all data providers ftp://lox.ucsd.edu/pub/rinex, $\mathrm{ftp} / / / g a r n e r . u c s d . e d u / p u b /$ rinex, and ftp://data-out.unavco.org/pub/rinex/obs who released data for free.

\section{REFERENCE}

Abdullah, M., Strangeways, H.J \& Walsh, D.M.A. 2009. Improving ambiguity resolution rate with an accurate ionospheric differential correction. Journal of Navigation, 62(1): 151166.

Anderson D \& Fuller-Rowell, T. 1999. The ionosphere: Space Environment Topics SE-14, Space Environment Center. Boulder.

Bagiya, M. S., Iyer, K. N., Joshi, H. P., Thampi, S. V., Tsugawa, T., Ravindran, S., Sridharan, R \& Pathan, B. M. 2011. Low-latitude ionospheric-thermospheric response to storm time electrodynamical coupling between high and low latitudes. Journal of Geophysical Research, 116(A1): A01303,

Bardford, W.P \& Spilker, J.J.J. 1996. Global Positioning System: Theory and applications, American Institute of Aeronautics and Astronautics, Vol. I and II Washington DC, USA.

Bernhardt, P.A., McCoy, R.P., Dymond, K.F., Picone, J.M., Meier, R.P \& Kamalabadi, F. 1998. Two-dimensional mapping of the plasma density in the upper atmosphere with computerized ionospheric tomography (CIT). Physics of Plasmas, 5: 2010-2021.

Best, C. L. 1991. Research methods in education. London: New York.

Daherty, P.H., Dehel, T., Klobuchar, J.A., Delay, S.H., Datta-Barua, S., de Paula E.R \& Rodrigues, F.S. 2002. Ionospheric effects on low-latitude space based augmentation systems, Proceedings of ION GPS 2002, September 24-27, 2002, Portland, pp. 13211329, Oregon.

Hajj, G.A \& Romans, L.J. 1998. Ionospheric electron density profiles obtained with the Global Positioning System: Results from the GPS/MET experiment. Radio Science, 33: 175190.

Kenpankho, P., Watthanasangmechai, K., Supnithi, P., Tsugawa, T \& Maruyama, T. 2011. Comparison of GPS TEC measurements with IRI TEC prediction at the equatorial latitude station. Earth Planets Space, 63: 365-370. 
Liu, L.B., Wan, W.X., Chen, Y.D., Le, H.J \& Zhao, B.Q. 2012. Recent progresses on ionospheric climatology investigations. Chinese Journal of Space Science, 32: 665-680.

Prikryl, P., Jayachandran, P.T., Mushini, S.C., Pokhotelov, D., MacDougall, J.W \& Donovan, E. 2010. GPS TEC, scintillation and cycle slips observed at high latitudes during solar minimum. Annales Geophysicae, 28: 1307-1316.

Rama Rao, P. V. S., Gopi Krishna, S., Niranjan, K \& Prasad, D. S. V. V. D. 2006. Temporal and spatial variations in TEC using simultaneous measurements from the Indian GPS network of receivers during the low solar activity period of 2004-2005. Annales Geophysicae, 24(12): 3279-3292.

Reshbeth, H \& Setty, C.S.G.K. 1961. The F-layer at sunrise. J, Atmos. Terr.Phys, 20: 263.

Warnant, R., Ivan, K., Marinov, P., Bavier, M \& Lejeune, S. 2007. Ionospheric and geomagnetic conditions during periods of degraded GPS position accuracy: 2.RTK events during disturbed and quiet geomagnetic conditions, Advances in Space Research,39(5): 881-888.

Yizengaw, E., Moldwin, M. B., Dyson, P. L \& Essex, E. A. 2007. Using Tomography of GPS TEC to Routinely Determine Ionospheric Average Electron Density Profiles, J. Atmos. Solar-Terr. Phys., 69: 314-321. 